\title{
ESPIRITUALIDADE E TRANSCENDÊNCIA NA PERSPECTIVA DE VIKTOR FRANKL
}

[SPIRITUALITY AND TRANSCENDENCE ACCORDING TO VIKTOR FRANKL'S THOUGHT]

\author{
Thiago Avellar de Aquino* \\ Universidade Federal da Paraíba, Brasil
}

\begin{abstract}
RESUMO: Este artigo procura aclarar o conceito de espiritualidade presente no pensamento de Viktor Frankl. Analisaram-se os principais livros onde o autor abordou a temática, o que possibilitou identificar que a sua compreensão deriva-se da filosofia da existência. Destacaram-se a concepção antropológica e a dinâmica do espírito humano tanto na busca de sentido como na realização da essência na existência. Por fim, demonstrou-se que os fenômenos espirituais se caracterizam por autotranscendência e autodistanciamento.
\end{abstract}

Palavras-chave:

Transcendência; Logoterapia

Espiritualidade;

\begin{abstract}
This article aims to clarify the concept of spirituality that is present in Viktor Frankl's thought. Therefore, we have deeply analyzed the main books in which the author addressed the subject, making possible to identify that his understanding derives from the philosophy of existence. In this sense, the anthropological conception and the dynamics of the human spirit have been highlighted, both in the search for meaning as well as in the realization of the essence through existence. Finally, it has been demonstrated that spiritual phenomena are characterized by the selftranscendence and self-distancing.
\end{abstract}

KEYWORDS: Spirituality; Transcendence; Logotherapy

$\mathrm{O}$ presente artigo teve por objetivo apresentar a perspectiva de Viktor Frankl (1905-1997) acerca da dimensão espiritual. Norteou-se pelo seguinte questionamento: Qual o significado da espiritualidade na perspectiva de Viktor Frankl? Para tanto, realizou-se uma revisão da literatura com o intuito de identificar a sua preocupação com a dimensão espiritual do ser.

Viktor Emil Frankl (1905-1997) nasceu em Viena e foi um importante analista existencial do século XX. Médico psiquiatra, neurologista e filósofo. Entretanto, a instantia crucis do seu pensamento foi a sua experiência como prisioneiro comum nos campos de concentração durante a Segunda Guerra Mundial. Como prisioneiro 119.104, passou pelo inferno de Auschwitz e foi selecionado por Mengele para os campos de trabalhos. Apenas perto do final da guerra, atuou como médico para cuidar dos prisioneiros contaminados com tifo. Após a guerra, descreveu a sua experiência do livro Ein Psycholege Erlebt das Konzentrationslager, descrito por Karl Jaspers como "um dos poucos grandes livros da humanidade" (Garcia Pintos, 2007). Assim, chegou a problematizar:

* Professor do Departamento de Ciências das Religiões da Universidade Federal da Paraíba. Email:tama_aquino@hotmail.com 
Que é o homem? Nós aprendemos a conhecê-lo como talvez nenhuma outra geração anterior o tenha feito; nós o conhecemos no campo de concentração, onde tudo que não era essencial foi jogado fora; onde lhe faltou tudo que havia possuído; dinheiro, fama, poder, felicidade, restando apenas o que o define como ser humano. Sobrou o que ele não pode "ter". O que ficou foi o próprio homem, em sua essência, queimado pela dor, dissolvido pelo sofrimento - o elemento humano em sua quintessência (FRANKL, 1978, p. 255).

Observa-se que a sua preocupação primeva foi a pergunta: Quem é o homem? Essa inquietação se tornou o fio condutor do seu pensamento, pois sua busca foi por uma imagem de homem mais próxima do ser humano concreto. Segundo Buber (1985), Kant teria proposto essa mesma pergunta como uma das questões para a filosofia no sentido universal. Da mesma forma, Frankl abordou esse questionamento em sua teoria inspirado a partir da tradição judaica: "Que é o homem, que dele tendes memória? Assim perguntou o salmista a Deus" (FRANKL, 1978, p. 253), o que levou a cabo a consecução de sua antropologia filosófica.

Desenvolveu uma perspectiva teórica e metodológica denominada de Logoterapia e Análise Existencial, que corresponde a uma forma de psicoterapia centrada no sentido da vida. Assim sendo, em termos de sua práxis terapêutica, a Logoterapia parte do espiritual, enquanto a análise existencial volta-se para o espiritual (FRANKL, 1978). Desse modo, torna-se imperativo compreender o significado do espiritual na perspectiva desse autor. $\mathrm{O}$ analista existencial considerou que:

A logoterapia não somente pressupõe o espiritual e o mundo objetivo do sentido e dos valores, como também se serve deles para fins terapêuticos. A análise existencial, por sua vez, não se limita a apontar o logos, entendido como aquilo que "se deve" em cada caso; vai mais longe: o que lhe importa é evocar a existência, definida como aquilo que sempre "se pode". (FRANKL, 1978, p. 198)

A dinâmica do espírito está inserida nesse movimento dialético entre o ser e o poder, nas palavras de Mounier (2004, p. 70) "[...] a vida espiritual é luta contra a inércia e o sono vital". Ademais, a análise existencial frankliana é uma análise orientada para a existência, ou seja, para a relação do homem com o mundo, com todas as suas implicações: liberdade e responsabilidade; ser e poder ser. Entretanto, alerta o autor que “a existência não é nem analisável nem sintetizável” (FRANKL, 1978, p. 198).

Dessa forma, conclui, por meio da análise existencial, que a existência, em última instância, é sempre uma forma de ser facultativa e acontece na dimensão espiritual, posto que, Ex-sistir significa sair de si mesmo e se colocar perante o psicofísico (FRANKL, 1995).

O animal não conhece, por conseguinte, nenhum antagonismo, vive sempre somente em paralelismo psicofísico - sempre somente do psicofísico unitário. $\mathrm{O}$ homem, porém, só começa justamente a ser homem quando é capaz de se opor ao seu próprio psicofísico (FRANKL, 1978, p. 165).

A visão de homem do autor tem profundas raízes na filosofia da existência, tendo em conta que "[...] é o próprio ser do homem como problema de si mesmo" (ABBAGNANO, 2006, p. 20). Conforme pensa Batalha (1968), o problema da existência converte uma unificação, pois o mundo é mundo para um indivíduo, todo objeto é objeto para um sujeito, assim como todo valor é valor para uma pessoa, o que torna o ser responsável tanto pelo que ele é quanto por tudo que existe no seu entorno. Assim, a transcendência para o mundo seria a pujança para superar a cisão homemmundo.

A filosofia existencial de Frankl compreende que o homem é um ser lançado no 
mundo e, por conseguinte, precisa fazer escolhas para, assim, definir-se a si mesmo como uma pessoa descente ou indecente, ou santo ou um ser hediondo. Assim, questiona novamente:

Que é, então, o homem? Indagamos de novo. É um ser que sempre decide o que é. Um ser que, em proporções idênticas, traz consigo as possibilidades de descer ao nível do animal ou se elevar à vida do santo. $\mathrm{O}$ homem é a criatura que inventou a câmara de gás; mas, ao mesmo tempo, é a criatura que foi para a câmara de gás de cabeça erguida rezando o Pai-Nosso ou com a prece fúnebre dos judeus nos lábios (FRANKL, 1978, p. 255).

Toda decisão se configura como uma constituição da essência do ser, ou uma transformação do ser a partir da ação no mundo. Destarte, o ser humano está sempre transformando as possibilidades (potentia) em realidades por meio da ação (actus) (Frankl, 1995). "O homem, efetivamente, assemelha-se a um escultor que trabalha com cinzel e martelo a pedra informe, de modo que a faz adquirir forma pouco a pouco" (FRANKL, 1989, p. 110). Nesse sentido, a pedra informe se constitui como a potência da existência, e o talhar com o cinzel, as decisões, que o faz configurar uma forma (essentia). Portanto, "cada ato é o seu próprio monumento" (FRANKL, 1978, p. 150), ou, nas palavras de Scheler (2003, p. 45) “a pessoa só é em seus atos e atrás deles”. Frankl faz a seguinte distinção entre Deus e o homem:

Somente Deus pode afirmar de si mesmo "sou o que sou". Pode fazê-lo porque é actus purus, potência atuada, possibilidade realizada. Deus é uma congruência de ser e ser-assim, de existentia e essentia. No homem, porém, há sempre uma discrepância, esta distância entre existência e essência são inerentes à vida humana como tal (FRANKL, 1978, p. 232).

Nessa direção, Frankl (1978) compreende que, ao decidir sobre algo (autodecisão), o ser humano também decide sobre quem ele será, em um processo de autocriação. Por esse motivo, o caráter de dever/missão da vida está imbricado no caráter de resposta à existência (FRANKL, 1992). Em outras palavras, a vida interroga o ser humano no aqui e agora, e esse, por sua vez, responde por meio de ações no mundo, o que resulta decisivamente na realização de sua essência. Por conseguinte, podem-se extrair duas conclusões: (1) o sentido na vida, que é ad personam e ad situationem, comporia, em sua totalidade, o sentido da vida; (2) apenas na morte coincidiria essência e existência, logo, no momento da morte, nasceria o ser. Assim, "[...] a vida do homem, e, com ela o 'seu' mundo, é fechada em si, logo que ele morre" (FRANKL, 1978, p. 153).

De forma geral, os temas de sua visão de homem e de mundo orbitam em torno da liberdade e responsabilidade humana na consecução da essência do ser, no hiato entre a concepção e a morte. Assim explica:

[...] a análise existencial absorve o homem, mas não só o absorve como também o responsabiliza. E exatamente nisso a análise existencial se distingue de maneira essencial de qualquer filosofia existencial, sobretudo do existencialismo francês; pois a responsabilidade já implica um 'pelo quê se é responsável', e, segundo a teoria da análise existencial, aquilo pelo qual o homem é responsável constitui a realização do sentido e de valores (FRANKL, 1995, p. 100).

No que se refere ao existencialismo, Frankl (1992) alega que, para Sartre, o homem deveria criar-se a si mesmo sem nenhuma referência, apenas ancorado no "nada". Essa perspectiva seria semelhante ao truque indiano na medida em que se poderia subir, de forma ilusória, por meio de uma corda que foi lançada para o ar. Ora, 
o ser humano, ao contrário, deve alçar a sua corda no seu dever-ser específico e concreto em sua existencialidade, para poder aperfeiçoar, continuamente, o seu ser-nomundo. Ademais, ele é puxado por e atraído pelos valores que brilham com mais intensidade em seu campo fenomenológico (FRANKL, 1978).

Por conseguinte, “o sentido da vida é a própria vida” (FRANKL, 1978, p. 231). Diante disso, esclarece Frankl que a palavra vida, nesse contexto, tem dois significados: o primeiro significa vida factual (o ser) e, o segundo, como missão a cumprir no campo das possibilidades de ser (pré-estágio do ser). Entretanto, para o desespero do homem atual, ele foi convencido de que estaria no vácuo, sem referências aos valores e sentidos em potência no seu vir-a-ser, pois seriam meras ilusões. Por esse motivo, aventou que

Não é, pois, verdade, como se diz com frequência, que o sentido da vida é suportar a sua falta de sentido, enfrentar o "absurdo" da existência. Pelo contrário, faz parte da vida não conseguir abarcar o todo, não compreender o sentido da totalidade nem demonstrá-lo (FRANKL, 1978, p. 234).

A sociedade industrial, na época de Frankl, e, nos tempos atuais, a sociedade pós-industrial, dificulta o ser humano a perceber sentidos e valores em sua existência, assim, de forma geral, ele tem dificuldade em descobrir pelo quê se sente responsável, colocando em dúvida a própria concretude do sentido. Em vista disso, alertava o filósofo do sentido, desde o século XX, que "o homem hodierno está enfadado do espiritual, e esse enfado do espiritual constitui a essência do niilismo contemporâneo" (FRANKL, 1995, p. 88). Por conseguinte, torna-se necessário a revalorização da sua dimensão mais humana, qual seja: a espiritual, tema que será discorrido a seguir.

\section{O Homem COMO Um Ser NoOLógico}

Segundo Heimsoeth (1982), o problema do ser espiritual foi um importante tema na filosofia, sobretudo nas ciências do espírito (Geisteswissenschaften). Da mesma maneira, Frankl está inserido nessa perspectiva na medida em que se afasta da Naturwissenschaften. Sobre o espírito, comenta Frankl:

[...] o espírito não é substância, mas puro movimento. Ouvimos antes que ele se pode caracterizar como o que se opõe, como o que se coloca "contra". Como tal, o que é espírito não pode nunca ser substância no sentido tradicional. Representa, pelo contrário, uma entidade ontológica, e de uma entidade ontológica, nunca se poderia falar como uma realidade ôntica, isto é, de substância no sentido tradicional (FRANKL, 1978, p. 165).

O conceito de espírito na Logoterapia é derivado do pensamento filosófico, sobretudo da concepção fenomenológica de Scheler (2003) - pensador que mais influenciou Viktor Frankl. Max Scheler utilizava também a palavra espírito para designar os fenômenos originários, tais como atos volitivos e a decisão livre, aquela pessoa espiritual que se manifesta no centro da esfera do ser. Para Scheler (2003, p. 45) “o espírito é o único ser que é por si mesmo incapaz de ser objetivado - ele é pura atualidade, só tem seu ser na livre realização de seus atos".

Frankl (1995), por sua vez, defende um núcleo espiritual em que se originam os fenômenos genuinamente humanos e que os faz distinto dos animais. A espiritualidade, para Viktor Frankl, não pode ser confundida nem muito menos reduzida à espiritualidade no seu aspecto religioso, posto que:

[...] utiliza a seguinte palavra da língua germânica para designar espiritualidade: 
Geistigkeit. Esse termo não se refere à vida espiritual-religiosa, mas antes aos valores e sentidos que o ser humano está imbuído. Dessa forma, ainda faz a distinção entre o subjektiv Geistige e o objektiv Geistige. A primeira expressão se refere à perspectiva do sujeito perante os valores e os sentidos, já a segunda, diz respeito ao sentido em si mesmo, como se encontra no mundo (Aquino, Véras, Braga Vasconcelos, Silva, 2015, p. 60).

A concepção de Frankl acerca dos valores coincide com a de Max Scheler à medida em que adota uma postura do "emocionalismo", pois adota a Ordre du coeur de Pascal. Hessen (1967, p. 130), interpretando Scheler, afirma que "Assim como apreendemos a sensação da cor no ato da visão - do mesmo modo apreendemos os valores no ato do nosso sentimento deles (Gefühlsakt)". Nessa direção, o órgão de apreensão dos valores seria o sentir intencional (intentionales Fuhlen), enquanto para Frankl (1989), o sentido seria apreendido de forma imediata e pré-reflexiva pela consciência intuitiva (Gewissen), pois essa seria, segundo o seu pensamento, o órgão do sentido. Dessa forma, os valores são objetos que se encontram no mundo, ou seja, brilham do mundo para a consciência valorativa (Gewissen).

A consciência seria definida "[...] como a capacidade de procurar e descobrir o sentido único e exclusivo, oculto em cada situação" (FRANKL, 1992, p. 68). A consciência seria um dos fenômenos transsubjetivos, pois sempre aponta para os valores e sentidos que se encontram no mundo. Nesse tocante, o autor coloca a ênfase na dimensão objetiva dos valores e dos sentidos, posto que se trata de algo a ser encontrado e não atribuído, refutando a primazia do subjetivismo. Nessa direção, o sentido seria tanto situacional quanto pessoal, enraizado na relação sujeito-mundo (FRANKL, 1989, 1995) como é representado no entrelaçamento do símbolo Yin-Yang (FRANKL, 1978).

A análise existencial frankliana propõe uma clarificação do sentido na existência concreta, considerando a relação do homem com o mundo. Para o autor em tela, se, por um lado, o ser humano pode captar o sentido a partir de sua compreensão ontológica pré-reflexiva dos valores, por outro, "O dever precede ontologicamente ao querer" (FRANKL, 1992, p. 45), o que propicia uma busca dinâmica de um sentido para a vida.

Constata-se, então, que tanto o psiquismo quanto o espiritual possuem suas próprias dinâmicas, enquanto a primeira se baseia nos instintos, a última se fundamenta na atração espontânea para os valores e sentidos existenciais. Assim, a dinâmica espiritual se movimenta a partir da fissura entre o ser e o poder ser, que se constitui, em última instância, uma tensão necessária na relação do homem com o mundo, na busca de concretizar a sua essência final.

Além da unidade homem-mundo, o pensador do sentido questiona acerca da fragmentação do ser humano: "Onde fica a unidade do homem? Que é que fizeram do ser-homem, que o destroçaram, pondo-o como cerâmica de cacos e rachaduras, de fissuras qualitativas?" (Frankl, 1989, p. 42). Nessa perspectiva, defende a unidade antropológica apesar das diferenças ontológicas, ou seja, uma unidade apesar das diferenças dimensionais, na qual configura uma imago hominis, que inclua a dimensão espiritual/noológica. Partindo desse princípio corolário da dinâmica do espírito humano, o pensador do sentido propõe uma ontologia dimensional, isto é, uma visão de homem que compreende a totalidade humana na unidade bio-psíquico-noológico que resulte em uma unitas multiplex (FRANKL, 2011).

[...] O homem é, apesar de tudo, unidade e totalidade. E nunca é demais enfatizar essa unidade e totalidade, porque não afirmamos, de modo algum, que o homem seja "composto" de corpo, alma e espírito. Ele é tudo isso, pelo contrário, 
unitariamente, mas só o espiritual constitui e garante esta unidade (FRANKL, 1978, p. 122-123).

Essa unidade do humano, por conseguinte, aproxima-se do conceito de pessoa na ótica de Frankl: compreende que "a pessoa espiritual-existencial do homem é um individuum, um in-summabile e um novum" (FRANKL, 1978, p. 129). Por ser unidade, a pessoa é indivisível, in-dividuum, logo, não é passível de fragmentação.

Ser humano não significa outra coisa senão ser indivíduo. Como tal, porém, está sempre centrado, centrado em torno de um meio, em torno do seu próprio centro. O que, porém, se encontra nesse centro? O que preenche esse meio? Lembremonos daquela definição de Max Scheler sobre a pessoa: Ele a entende como detentora, mas também como "centro", de atos espirituais. Sendo, porém, a pessoa aquela da qual se originam os atos espirituais, ela também constitui o centro espiritual em torno da qual se agrupam o psicofísico (FRANKL, 1992, p. 20).

No que confere à totalidade do ente humano, o autor assevera que a pessoa espiritual não pode ser compreendida como um somatório de dimensões, por isso, se configura como in-summabile. Por fim, cada pessoa é um novum absoluto, o que significa que aquilo que se transmite é apenas o organismo, mas não a pessoa espiritual; em outras palavras, herdam-se os tijolos, mas não o construtor (FRANKL, 1978; 1988). $\mathrm{O}$ autor, então, conclui que:

O físico é dado pela hereditariedade - o psíquico é dirigido pela educação; o espiritual, contudo não pode ser educado, tem de ser realizado - o espiritual "é" só na autorrealização, na "realidade da realização" da existência (FRANKL, 1978, p. 131).

Considerando a unicidade e irrepetibilidade do ser, Frankl se aproxima da ótica de Max Scheler quando esse último afirmou que "o homem é o $X$ que pode se comportar 'abertamente para o mundo' em uma medida ilimitada. A gênese do homem é a elevação até a abertura do mundo por força do espírito" (SCHELER, 2003, p. 38). A singularidade da existência humana advém da liberdade da vontade, com a qual permite o ente escolher quais possibilidades passarão para a existência (realidade), preservandoas da transitoriedade; e quais possibilidades se encaminharão para o nada. Por sua constituição existencial, o ser humano sempre é questionado pela vida e, ao responder, torna-se responsável por sua essência.

Nesta direção, nos planos somáticos e psíquicos, o ser é interpretado apenas como um sistema fechado, resultante de reações fisiológicas e psíquicas. Apenas na medida em que se inclui a dimensão noológica se desvela a sua autêntica essência, qual seja, um ser aberto para o mundo (Frankl, 1989). Destarte, o empreendimento da filosofia da existência de Frankl foi o de compreender a dinâmica do espírito humano, ou seja, a noodinâmica, que tinha por escopo clarificar as aspirações espirituais do ser e sua busca por um sentido na existência.

Dessa forma, aquilo que é especificamente humano, distingue-se dos fenômenos originados no psicofísico, posto que "o homem é algo mais que seu psiquismo: o homem é espírito. Pelo mero fato de sua autotranscendência se distanciar do plano do meramente biopsicológico e entrar na esfera do especificamente humano, a dimensão noológica" (FRANKL, 2003, p. 74-75). Nessa perspectiva, a espiritualidade se caracteriza tanto pela autotranscendência, que seria o modo genuíno de ser humano, quanto por atos que afirmem a liberdade e a responsabilidade. Constata-se aqui que o espiritual não coincide com a concepção religiosa, por esse motivo, utiliza-se o termo noológico, para indicar os fenômenos especificamente humanos (FRANKL, 2003). 
Segundo o autor da psicologia do sentido da vida, em sua compreensão acerca da ontologia dimensional, os fenômenos humanos têm sua origem no núcleo espiritual, o que constitui a pessoa autêntica. Entretanto, as ciências naturais apenas adentram na bidimensionalidade do psicofísico, apreendendo o ser de forma parcial, o que poderia ocasionar reducionismos na apreensão dos fenômenos, já que, fenômenos como a criatividade, o amor, a consciência (Gewissen) têm sua gênese na dimensão mais elevada do ser.

Destarte, a dimensão noológica, por ser mais ampla, deve integrar e abarcar as demais. Nessa perspectiva, na medida em que se amplia a expressão dos fenômenos espirituais, mais humano seria o ser humano. $\mathrm{O}$ autor em tela concluiu que essa dimensão diferencia qualitativamente o homem dos animais, portanto, também possui a sua própria dinâmica, não em um campo psíquico fechado em si mesmo, mas em seu campo existencial de abertura para o mundo, pois ser Homem significa estar e ser além de si mesmo.

Quando emerge a dimensão especificamente humana? Nessa esteira, "a pessoa espiritual comporta-se, em relação ao organismo, de modo análogo ao músico em relação ao seu instrumento. Uma sonata não pode ser tocada sem piano nem sem pianista" (FRANKL, 1978, p. 117). Frankl explica que, após o espiritual adentrar no psicofísico, a priori, permanecerá oculto no invólucro no organismo psicofísico, até que um dado momento possa emergir e se expressar por meio deste. Da mesma forma ocorreria no fenômeno da música, o cantor, por exemplo, utiliza-se das cordas vocais como campo de expressão de um fenômeno mais profundo que corresponde ao valor denominado arte. O fenômeno do amor, por sua vez, também abarcaria essa unidade e totalidade, posto que se expressa por meio do psicofísico, mas sua origem adentra na pessoa espiritual profunda.

Os atos espirituais, em sua origem, não são passíveis de reflexão, ou seja, são pré-reflexíveis. Por esse motivo, um dos atributos da consciência (Gewissen) é que ela é intuitiva, considerando que a profundeza do logos não pode ser apreendida por meio da razão. No Eros, há uma intuição das possibilidades de ser do ente amado e no estéticoartístico, a intuição dá lugar à inspiração do espírito criativo. Por esse motivo, Frankl compreende que deve haver uma fé no sentido oculto, que em alguns momentos se desvela para o ser. Em suas palavras, considera que:

A fé do ser humano no sentido é uma categoria transcendental, na acepção usada por Kant. Assim como sabemos desde Kant que de certo modo não tem cabimento fazer perguntas que transcendam tempo e espaço, pela simples razão de que não podemos pensar e, portanto, não conseguimos fazer uma pergunta sem pressupor tempo e espaço - da mesma forma o ser homem (menschliches Sein) sempre já é um ser em função de um sentido, mesmo que não o conheça (FRANKL, 1992, p. 61).

Assim, o autor em foco defende a existência de uma fé incondicional no sentido oculto, o que pode se constituir como uma autêntica espiritualidade. Ademais, na medida em que compreende a consciência intuitiva como um órgão aberto para o mundo, demonstra sua característica principal, qual seja, o seu caráter transcendente, tanto no sentido horizontal, para os valores e sentidos, quanto no sentido vertical, em sintonia com a "lei eterna" (FRANKL, 1992).

\section{CONSIDERaÇões Finais}

A pergunta norteadora do manuscrito foi: Qual o significado da espiritualidade 
na perspectiva de Viktor Frankl? Pelo exposto, o espiritual, segundo o autor, seria uma dimensão constitutiva do homem, já a espiritualidade poderia ser compreendida por meio da dinâmica existencial no espaço entre o ser e o dever-ser. Ademais, na medida em que o ente escolhe e responde às demandas da vida no seu espaço de liberdade, converte-se em um ser responsável. Destacou-se ainda que, para Viktor Frankl, a dimensão espiritual se constitui fundamentalmente por aqueles fenômenos genuinamente humanos, os quais não são compartilhados com os animais e se caracterizam por dois movimentos: o da autotranscendência e o do autodistanciamento, que constituem caminhos para desvelar uma missão existencial. Conclui-se, portanto, que o sentido da vida para o autor é construir a própria essência na temporalidade da existência, o que se consolidará apenas no momento da morte.

\section{REFERÊNCIAS}

AQUINO, Thiago; VÉRAS, Alan, BRAGA, Daniel; VASCONCELOS, Sarah \& SILVA, Lorena. Logoterapia no contexto da psicologia. Reflexões acerca da análise existencial de Viktor Frankl como modalidade de psicoterapia. Revista Logos e Existência, 4 (1), 45-65, 2015.

BATALHA, Wilson de Souza Campos. A filosofia e a crise do homem: Panorama da filosofia moderna de Descartes a Sartre. São Paulo: Editora Revista dos Tribunais, 1968.

BUBER, Martin. ¿Que es el hombre? México: Fondo de Cultura Económico, 1985.

GARCIA PINTOS, Claudio. Un hombre llamado Viktor. Buenos Aires: San Pablo, 2007.

FRANKL, Viktor. Fundamentos antropológicos da psicoterapia. Rio de Janeiro: Zahar Editores, 1978.

FRANKL, Viktor. A presença ignorada de Deus. São Leopoldo: Editora Sinodal; Petrópolis: Vozes, 1992.

FRANKL, Viktor. Logoterapia e análise existencial. Campinas: Editorial Psy II, 1995.

FRANKL, Viktor. La vonluntad de sentido. Barcelona: Herder, 1998.

FRANKL, Viktor. Psicoterapia e sentido da vida. São Paulo: Quadrantes, 1989.

FRANKL, Viktor. Psicoterapia y existencialismo: Escritos selectos sobre logoterapia. Barcelona: Herder, 2003.

FRANKL, Viktor. A vontade de sentido. São Paulo: Paulus.

HEIMSOETH, Heinz. A filosofia no século XX. Coimbra: Arménio Amado, 1982.

HESSEN, Johannes. Filosofia dos valores. Coimbra: Arménio Amado, 1967.

SCHELER, Max. A posição do homem no cosmos. Rio de Janeiro: Forense Universitária, 2003. 